\title{
Television and Content Censorship: The Impact of 'Violent' Content on the Developmental Stages in the Personality of the Nigerian Child
}

\author{
Okim-Alobi Oyama and Silk Ogbu
}

School of Media and Communication, Pan-Atlantic University, Lagos, Nigeria

\begin{abstract}
Erik Erikson's theorization of the psychosocial developmental stages of humans, reveal the fragility of children with special attention to their biological and psychosocial characterization. The adolescent age is the period where the child is adventurous, curious and eager to explore, as he becomes fascinated with the media and begins to try out behaviours and lifestyles of his opinion leaders. The Nigerian child is more or less enthralled about foreign movies, shows and musical videos characterized by violence, thuggery, gangsterism, drug abuse, obscenity, and even promiscuity which are sometimes too much information for him to handle given his developing, immature and fragile psychology which makes it easy for these contents to influence his behaviour in every stage of his personality development as he is exposed to them. This Too Much Information (TMI) seems to be a product of media imperialism as local television contents in Nigeria, camouflaged in the concept of Americanisation and westernisation and devoid of censorship, are persistently consumed by adolescents in Nigeria. Hinged on Erikson's theory of personality developmental stages in a child and Bandura's social learning theory, this paper employs secondary data and a critical document analysis of previous research works to objectively opine and conclude that exposure to too much information (violent contents) on television can influence the psychosocial development of the personality of the Nigerian child.
\end{abstract}

Keywords: Nigerian Child; Aggression; Personality development; Television, Censorship; Violence; Catharsis; Psychology; Society

\section{Introduction}

According to Sokol (2009), Erik Eriksson was one of the first psychologists to propose a life-span theory on the development of humans which include eight psychosocial developmental stages with each stage associated with an inherent conflict or crisis that the individual must encounter and successfully resolve before proceeding to the next stage in his or her development. To Eriksson, the human life undergoes an 
eight-stage developmental process which is integral to the overall growth and development of the personality of the human being. However, Eriksson focused on adolescence which is the main crux of which this paper is built on. To Eriksson, the teen years are indeed a time of turning point of increased vulnerability and heightened potential (Eriksson, 1968). The teenager is aware of the potentials he has and so at this point he wants to experiment and learn new things. Fleming (2004) warns that teens should not merely learn who they are, but that they must learn to define and invent themselves. This is why identities are tried out like new suits of clothes such that parents, teachers, celebrities and criminals become role models for these teenage children; depending on who the teenager interacts with often or who he holds dear as that person begins to become an influential person to the teenager.

In an era where access to information is not rocket science, and teenagers these days own sophisticated apparatuses like: smartphones, tablets, laptop computers and other devices that give them easy assess to any information at any given time, one could only wonder what kind of information is available and gets consumed frequently by teenagers. Since the internet has Too Much Information (TMI) which can easily be accessed with these sophisticated devices teenagers own and use, there is a convergence in the media habit as television, radio, newspapers and magazines are all merged and can be accessed through the internet which offcourse would mean therefore that it is quite easy and somewhat inexpensive to have access to films, videos, TV shows, musicals and reports especially on the internet.

Because the teenage and adolescent years is a time when teens begin to tryout new identities, behaviours and characters, whoever the teen interacts with at this period is very influential in the life of that teenager. Since teens own smartphones and tablets and are always on the internet, a lot of them spend time downloading and watching movies, shows, drama and other contents with their phones which could only suggest that celebrities become their role models rather than their parents who may or may not be too busy to keep an eye on them.

Depending on what celebrity the teenager is obsessed with, if he loves action movies and thrilling shows where violence is the theme and is constantly promoted, these television contents begin to have an impact on the life of the teenager. In fact, research has shown that frequent exposure to violent media contents can stimulate violent behaviours on the viewers of these violent contents. One of such research that has shown that exposure to violent contents on television can influence children and teenage behaviours is the bobo doll experiment conducted by Albert Bandura in 1961 and 1963, which led to his theorisation of the social learning theory later in 1971. Bandura (1971) discovered that exposure to violent contents on television can influence or even purge out the violent tendencies of the viewers of these violent television contents especially among children.

Since television is an audio-visual system and technology that deals with two important senses: hearing and sight, the issue of believability is easily answered as television is considered to be a very powerful and persuasive medium.

Bandura's Bobo Doll experiment in 1961 and 1963 led to the theorisation of two sub-theories under his social learning theory. First, he found out that exposure of children to violent contents on television can trigger violent behaviours and aggression among children (Aggression theory) (Bandura et al., 1961). He also discovered in his other studies that rather than exposure to violent television programming triggering violent behaviours among viewers; exposure to violent television contents can purge out violent behaviours and tendencies in children (Catharsis theory) (Bandura, 1977). While some scholars try to take sides with the two schools of thought, other researchers have even questioned the validity and reliability of both the aggression theory and the catharsis theory. They have discredited the possibility of the aggression theory and catharsis theory being true. These studies have questioned the concepts on which the aggression and catharsis theory were postulated. One of these researchers is Gentile (2013), who gave four reasons to discredit the catharsis and media violence (Aggression) theories. He opposed the Freudian assumption that aggression must be vented saying it is not a drive. He disagreed that modern violence is not constructed in the way Aristotle postulated it to be and that it is not necessary to achieve catharsis. Gentle (2013) revealed that Aristotle had described that poetics and literary plays arouse emotions of pity and fear but not violence 
in the way modern violence is constructed, hence catharsis is more of a purification than purgation of emotions. Gentle argues that catharsis has never been proven in the hundreds of research conducted, and finally that catharsis is senseless because considering the mechanics of the brain, our learning increases everytime we see something and therefore is not possible that we are not likely to learn something through practicing, reading or even seeing it again. But looking at media violence and catharsis theories from the Nigerian perspective, exposure to violent television contents seem to influence violence in children, especially when some studies have been carried out in Nigeria to prove this hypothesis. For example, Adekoya \& Ogunola (2014) in their research, found out that participants who were exposed to watching violent movies reported higher level of aggression than those who were exposed to non-violent movies. In addition, Rishante \& Yakubu (2014) also concluded in their research among students of a secondary school in the Northern part of Nigeria that exposure of children to violent television content increases aggressive behaviour in them when the line graph showed that the group with exposure to visual graphical aggression content achieved a higher mean score for an aggressive behaviour. This position is also supported by the research conducted by Brown \& Bassey-Duke (2014) in Calabar, Nigeria where they found enough evidence to prove that street boys who displayed violence and aggression admitted that they regularly watched action movies that promoted violence and aggression. These findings support the assumption of this paper that some Nigerian teenagers who watch violent television shows like World Wrestling Entertainment, Jerry Springer Show or Hollywood Action Blockbuster movies like Rambo, Commando, etc., are likely to be influenced in regard to how they behave and react after watching these violent contents on television.

Even though Gentile (2013) discredits the theories of aggression and catharsis, this study evaluates how the exposure to violent television contents can influence the psychosocial developmental stages of the personality of the Nigerian child. It employs the use of secondary data in the evaluation, interrogation and analysis of this discourse as well as combines documentary and comparative analysis where studies and research work already exist. Hinged on Erik Erikson's psychosocial personality development theory and the Albert Bandura's Social learning theory with emphasis on the Aggression theory, this paper evaluates how exposure to violent contents on television can affect the psychosocial development of the personality of the Nigerian child. It also makes recommendations on how censorship can be better enforced for children to guard them in the viewership of certain contents on television especially contents with adult themes.

\section{Theoretical Frameworks}

\subsection{Erik Erikson's Psychosocial Personality Development Theory}

Erik Erikson's psychosocial personality development theory opines that the development of the psychosocial personality of the child, are in developmental stages, and each stage is integral because of the interactions and rapport the child has at that moment. Whoever has more interactions with the child at that moment tends to influence the behaviour and personality of the child. The teen years or adolescent years are very crucial years because it is the time where the teenager has increased vulnerability and heightened potential (Eriksson, 1968), and so the adolescent is eager to know things and begins to try out identities like new suits. During this period, the teen's role model could be parents, teachers, celebrities or even criminals. Because of the advent of information technology, teenagers and adolescents these days have access to Too Much Information because of the presence of the internet and the World Wide Web. The reality of today is that teenagers own smart-phones, tablets, computers and other sophisticated devices which grant them easy access to any kind of information, at any given time at little or no cost. Radio, television, newspaper and magazines have been converged on the internet such that with a smart phone or any sophisticated device they can surf the net, download movies, stream shows, read newspapers and magazines and listen to online radio stations and musicals with little or no cost. Thus, it has really become easy for teenagers to get all kinds of media content themselves since the advent of the internet. 
The adolescent has the liberty to access any kind of information at any given time with no supervision and censorship. He gets addicted to watching movies, shows, and reading all manner of materials that could contain violence or other adult themes without parental guidance or restriction. Since their smart-phones or tablets are what these adolescents spend time on and interact with almost every time, it is likely that their role models at this point may not be their parents but celebrities, artistes, wrestlers, and even criminals, depending on what media content he exposes himself to. These role models begin to have an impact on his life, they soon start talking like their celebrity role model, acting like them, dressing like them and even behaving like them, and so depending on the show, movie or any other content the adolescent consumes and exposes himself to, he may begin to exhibit the behaviours and actions of his role models which is likely to affect his attitudes, behaviours, values, perceptions and beliefs. These actions and behaviours can influence the adolescent's lifestyle and his personality or cognitive development. For example, while growing up some people liked to watch wrestling and action movies. At that time, being like Sean Michaels, Bret the Hitman, Hulk Hogan, Rambo or Commando was probably the priority of many teenagers who watched these television shows together and tried out whatever wrestling moves or tactics they had learnt from those movies. Today, the situation has not really changed as contemporary studies tend to indicate the consistency in this trend as would be exhaustively discussed in the later part of the paper.

\subsection{Social Learning Theory}

Bandura (1971), carried out an experiment where he observed children's behaviour after they were played a tape where a child was seen beating up a bobo doll on television. Bandura discovered that, after the children who were confined to a room had watched the behaviour on television, they all imitated the aggressive and violent behaviour by attacking the dolls put together with them in the room. He found out that children if exposed to violent content on television can become aggressive and violent, hence the aggression theory. However, Bandura study also revealed that exposure to violent behaviour on television can purge out the aggressive feeling and emotions from one. He drew this conclusion after observing that only one child refused to imitate that hostile, violent and aggressive behaviour, rather he sat still watching what the others were doing. He called that the catharsis theory. The social learning theory houses two main theories: aggression and catharsis theories.

\subsubsection{Aggression Theory}

In the aggression theory, exposure to violent television contents can trigger a violent or aggressive behaviour (Bandura, 1971). From his experimental observations on children, Bandura discovered that children are highly influenced by what they see. If they consume violent contents on television, there is a tendency that they are likely going to be violent by practicing what they have seen on television. Tapping from the postulations of Erik Erikson's psychosocial personality development theory, children are fragile with intense curiosity to know more. Their exposure to violence on television, especially if these violent or aggressive behaviours are played or exhibited by their role models like celebrities, parents, guardians, etc can motivate them to follow suit or behave like those characters they idolize (Fleming, 2004). They may want to experiment as they become curious about trying out what they have watched on television and what have been sunk into their subconscious. Sometimes, these aggressive behaviours continue with them through adulthood unless there are interventions that may result in a positive change of behaviour.

\subsubsection{Catharsis Theory}

In the catharsis theory, exposure to violent television content, rather than motivate one to become violent can actually purge out those violent and aggressive behaviours and emotions in children. The catharsis theory is a direct opposite of the aggression theory, and it argues that exposure to violent television contents cannot trigger or cause a child to become violent because those aggressive and violent emotions are purged out. Like the child observed in Bandura's bobo doll experiment, some children can actually be afraid of violence and aggression by watching violent contents on television. When a child sees the danger of violence 
Oyama et al., Adv. J Social Sci.; Vol. 1 Issue 1, pp: 30-39, November 2017

and aggression, according to the catharsis theory the child may not feel the urge to exhibit violent and aggressive behaviours since these urges are purged out. This also helps to shape the personality of the child as he develops psychosocially.

\section{Basic Constructs}

\subsection{Television}

The US Federal Communications Commission (2003), describes television as a technology that performs three basic functions which include converting images and sounds into electronic signals, sending these signals from the original point to a receiver (also known as a television set) and then converting the electronic signals back into images and sounds. With this description, television is an audio-visual device that transmits pictures or images (video) and sounds (audio) using electromagnetic signals into a receiver that is popularly referred to as a television set. Since its invention in the early part of the1950s, it has become an integral part of the American culture and lifestyle (Pisharody, 2013). Television has developed and its technology has revolutionised since 70 years ago when it was founded by John Logie Baird's mechanical scan system. Today television uses highly sophisticated and advanced technological systems to transmit rich entertaining, informative and educative contents over rebranded television sets or receivers. Today, television exist in more advanced form like smart TVs, LED, and plasma. Television broadcast its signals using certain frequencies like Ultra High Frequency (UHF) and Very High Frequency (VHF).

In Nigeria, television broadcasting started in October 31, 1959 in Western Nigeria with the establishment of the Western Nigeria Television (WNTV) by the regional government then headed by Chief Obafemi Awolowo (Egbon, 1982).The National Broadcasting Commission (2014), revealed that two other stations: Eastern Nigeria Television (ENTV) and Radio Kaduna Television (RKTV) were also established by their various regional governments in 1960 and 1962 respectively. But, the Federal Military Government through the promulgation of Decree 24 in May 1977, which already had effect from April 1976 gave birth to the formation of the Nigerian Television Authority (NTA), the only body empowered at the time to undertake television broadcasting in Nigeria (National Broadcasting Commission, 2014). Ten existing television stations including: Western Nigerian Television (WNTV), now NTA Ibadan; Eastern Nigerian Television (ENTV), now NTA Enugu; and Radio Kaduna Television (RKTV), now NTA Kaduna and FRCN Kaduna, were all merged to give birth to the Nigerian Television Authority (NTA), making it the first and oldest television station in Nigeria.

While Umeh (1989) argues that television broadcasting in Nigeria has been motivated by politics and education as politicians used it as instruments to carry out a blatant propaganda while using it to promote education in the country. Adegbokun(1983) asserts that the creation of states and the performance of the older television stations, led to the establishment of state-owned television stations and so television began to grow until the media got privatised to allow business entrepreneurs to invest in television which had become very influential in the society and also expensive to operate.

\subsection{Censorship}

Lessig (1999) defines censorship as the deliberate action to stop, silence or constrain contrary or controversial views. Censorship is generally understood to be the official suppression or prohibition of forms of expression (Moore, 2013). Butler (1997) stated that censorship can be done in two ways: State censorship or Private censorship. In State censorship, it is the government of the nation that prohibits the broadcast and media consumption of contents on the media. For example, in the early press in the UK, where the Authoritarian theory of the press applied, the press was censored as there were no liberalisation and freedom in the use of the media to send information among one another. People were prohibited from having free access to the media. This is also synonymous with the position of the Soviet normative theory which posits that the media should serve the interest of the party, as any information that is not in consonance with the Soviet party is censored (Benson, 2008). In Nigeria today, government censors contents on television through its regulatory agencies like the National Broadcasting Commission (NBC) 
and the Broadcasting Organisation of Nigeria (BON). These organisations or agencies work in accordance to the ethical codes of broadcasting, where contents that defame and are obscene among other tenets are prohibited from being broadcasted over the airspace. In private censorship, media owners tend to exercise control and authority over what is published on the media through "gatekeeping".

\subsection{Violence}

According to Olewus (1999) as cited in O'Moore (2002), violence refers to the use of physical force where the actor or perpetrator uses his or her own body as an object (including a weapon) to inflict (relatively serious) injury or discomfort upon an individual. As a matter of fact, Govier (2008), identifies intentional killing, beating, assaulting, torturing and wounding, as violent methods. The National Coalition on Television Violence (NCTV) in 1994 clarified that accidents, emotional displays, horseplay, slapstick, threats and sports activities are not included in their guideline as acts of violence.

Television violence has the greatest potential for both short-term and long-term effects upon children (Adekoya \& Ogunola, 2014). It encourages bullying which is also an act of violence. While few think it is mild, it may not be, as bullying can push children into committing suicide, being violent and even constituting a form of nuisance in the society.

\section{The Traditional Role of Television as a Form of Media}

Television has been identified as an audio-visual technology that converts frames of images and sounds into electromagnetic signals, which is relayed through a transmitter to a receiver also known as a television set. As a traditional form of media, television is the strongest of all the forms of media. This is because it deals with two major senses which are: sight and hearing, while other forms of media deal with one sense. Since television has this advantage over other forms of media, there is no doubt that it is a very powerful instrument for communication. Lasswell (1948) identified three functions of the media, which include: Surveillance of the environment, correlating with the environment and transmission of social heritage. But Wright (1960) added entertainment as the fourth function of the media, while Schramm (1964) elaborates all the functions of the media listed above.

In performing the role of providing surveillance to the environment, television gathers information and disseminates it to its audiences, provides information about events and condition of societies and the world, while also facilitating innovation, adaption and progress through this informal role. Television gathers information for the society and distributes this information all over the world. With the surveillance function of television already in play, television helps to interpret or correlate the information within the environment. Sometimes the complexities of information that has been gotten from surveillance could be complicated and would need to be interpreted. It is during the interpretation function of television, that certain contents are censored because these contents could influence the psychosocial development of the personality of the child. The Nigerian child consumes so many things while watching television. Erik Erikson, a renowned psychologist and sociologist theorised that the development of the human being is in stages, and each stage is integral to the psychosocial development of the child because of the interaction the child has at that stage. Children who watch violent cartoon shows tend to act violently given the postulations of Erikson's personality development theory and the fragility of the psychology and mentality of children.

\section{The Impact of "Violent" Content on the Personality of the Nigerian Child}

Moeller (1996) acknowledged that available literature suggests that the content of television can have four broad types of effects on people. They include behaviour, attitudes, beliefs or values, and knowledge or cognitive skills. Nigerian children like other children learn by interacting with contents on television. Hollywood blockbuster action movies which seem to be one of the main television contents consumed by the contemporary Nigerian child appears to influence their psychosocial behavioural mechanics as these movies heap series of unforgettable images or frames in the subliminal minds of the Nigerian child. These 
Oyama et al., Adv. J Social Sci.; Vol. 1 Issue 1, pp: 30-39, November 2017

frames build mounds on the subconscious of today's youths who tend to allow the frames to influence their behaviours as they believe that acting "immodestly" brings a term called "swag" that is synonymous with the lifestyles of celebrities. There are several studies that have been carried out to prove that exposure to violent television contents can influence violent behaviours among children or teens who watch them. The earliest of these studies was the Bobo Doll Experiment carried out in 1961 and 1963 by Albert Bandura. Here, children were exposed to violent television videos showing an adult hitting and kicking the Bobo Doll, and after a while, these children were left alone with these dolls, and immediately they began to imitate the adult by kicking, hitting and even trying to strangle them. Bandura used this experiment to theorise the Social learning theory in 1971 where he attributed the hitting and kicking of the dolls by children to the exposure to the video they watched about an adult hitting the bobo doll. He described this act as "modelling" which connotes a process by which an individual learns a behaviour by observing another (Bandura, 1971). In Nigeria, they have been studies carried out to show that exposure to violent media contents can influence aggression and violent behaviours by adolescents and young children. One of these studies was carried out in a secondary school in Ago-Iwoye, Ogun State, Nigeria, where 199 students were shown video films with violent scenes for a particular period of time after which their level of aggression was examined after watching the films and compared with the students who were exposed to non-violent movies. Adekoya \& Ogunola (2014), found out that participants who were exposed to watching violent movies reported higher level of aggression than those who were exposed to non-violent movies $(t=3.593$, $\mathrm{df}=197, \mathrm{p}>0.05)$. The result went further to show that female participants reported a higher level of verbal aggression than the males $(t=0.002 \mathrm{df}=197, \mathrm{p}<0.05)$.

In hypothesis one which stated that participants exposed to violent media contents exhibit higher level of aggression than those who watched non-violent movies, the study confirmed that participants exposed to violent media contents exhibit higher level of aggression than those who watched non-violent movies. This revealation aligns with the findings of Bandura's study which suggests that teenagers behave aggressively and tend to imitate aggressive behaviours from the violent movies they were exposed to.They concluded that young children need to be monitored to know what media contents they watch and recommended that they should be supervised in selecting what they watch on television because they could easily be influenced into imitating actions or behaviors from the television contents.

Expanding the study, Huesmann and Eron (1986) in Rishante \& Yakubu (2014) opine that children learn how to become aggressive in novel ways by wondering whether being aggressive towards others will be rewarding to them simply through watching aggression on television. This could mean that some children become aggressive or violent because they think it is rewarding or somewhat gainful. But Christakis \&Zimmerman (2007) even go further to deduce violent behviours from children after exposure to television based on gender. They found out that boys who viewed violent television programming at the age of 2 to 5 years are prone to amplified risk for antisocial behaviour at the age of 7 to 10 years. In an interesting study, Rishante \& Yakubu (2014), randomly selected 90 students (42 males and 48 females) between 8-16 years, schooling in the North central geo-political zone of Nigeria, to investigate the influence of media sex and violence on children. Their research showed the mean score on aggressive behaviour across the study groups. This indicated that, the study group that were exposed to an audio-visual clip on marine life had a mean aggression score of 52.03, the group who were exposed to a video clip with a high level of violent content had an aggression mean score of 69.77 , while those who were exposed to a sex education video clip had 46.4 as its aggression mean score.The line graph showed that the group with exposure to visual graphical aggression content achieved a higher mean score on aggressive behaviour.

In their second hypothesis which stated that "violence in the media will have a significant impact on children's behaviour", the results revealed that children exposed to media violence outrightly had higher aggressive attitudes than children with no exposure to violent media content, $F(2,87)=11.946, p=0.0005$ $(\mathrm{p}<.05)$. Their research concluded that exposure of children to media violent contents lead to aggressive behaviour. In the same vein, Villani (2001), opine that the principal effects of media exposure to violent contents on television are increased violent and aggressive behaviour, increased high risk behaviours, 
including alcohol and tobacco use, and accelerated onset of sexual activity. In addition, televised violent programmes influence children, and television influences teenage violence (Chibuokwu, 2013). The social learning theory which houses two main theories (Aggression and Catharsis theories) tends to show that great exposure to violent television or film contents can either precipitate violent or aggressive behaviours or purge these behaviours out. World Wrestling Entertainment shows and blockbuster action movies support the postulations of the social learning theory. These assumptions are supported in the works of Osofsky (1999), which affirms the claim that youth exposure to media violence leads to increased aggressiveness.

\section{Discussion}

As earlier stated, television is the most powerful and influential form of media because of its sense of sight and hearing since it is an audio-visual device. It could have a tremendous influence on the psychosocial development of the personality of any child especially one who is continuously hooked to a television. With the world speedily becoming a global village, it is no longer news that technological advancement has made life quite easy, as smart devices and computers have been invented to provide quick and easy access to any information in any format (video, audio, text, graphics and pictures) at any given time courtesy of the internet. While this technological radicalisation could be seen as a breakthrough in the easy acquisition of information, the problem of censorship becomes apparently worrying as these smart devices give the Nigerian child unlimited access to Too Much Information (TMI) which could be problematic, as they tend to let what they are exposed to influence their behaviours, attitudes and personalities.

From the studies discussed and evaluated here, there is evidence to prove that violent television contents can influence violent and aggressive behaviour in children: a hypothesis tested and proven in Albert Bandura's Bobo Doll Experiment based on the social learning theory, as well as other works conducted globally and in Nigeria. Although, scholars like Gentile (2013) have made conclusions disregarding the Aggression and catharsis theories, this study shows that there is enough evidence and proof to show that exposure to violent television contents can influence the psychosocial development of the personality of the Nigerian child. Cartoons like: "Spiderman", "Ben 10", "Batman", "Turtle Ninjas" contain violent themes that can be misinterpreted by children. "Tom and Jerry" a popular cartoon for kids in the early $21^{\text {st }}$ century which portrays the typical life of a cat and mouse where they both plan on how to hurt each other could be misinterpreted by the child to mean that it is okay to be violent or that being aggressive to others is okay. With this exposure to such cartoons, children may begin to imitate these violent and aggressive behaviours as seen and portrayed in the cartoons and movies they watch.

\section{Conclusions}

After thoroughly evaluating some secondary data and extensively reviewing related literatures of previous works in this subject, this paper hinged on two major theories have demonstrated that indeed teenage exposure to violent television contents influence the psychosocial development of the personality of the Nigerian child as he interacts with his environment. Unfortunately, globalisation has made information easily accessible such that the Nigerian child consumes music, videos, audio, text and graphical images with strong adult themes (too much information) on television.

It is for this reason this paper therefore recommends that:

- Violent television messages should be censored to guide the development of the personality of the Nigerian child.

- $\quad$ Parents should take better measures to ensure that certain sites with serious adult themes are not made accessible to their children on their smart phones and computers. They should make use of the parental control feature on cable networks and television channels to prevent their children from having access to certain channels.

- Children should not be allowed to watch cartoons with violent themes. This is because these cartoons promote violence and aggression which is subconsciously imprinted on the child's mind and tends 
to affect his personality or traits. Children should only watch cartoons under adults or parental supervision.

- $\quad$ Parents should provide more educative contents on the devices of their wards to fill the gap that aggressive contents are currently filling. These contents can help to mould their personality in a better way rather than letting violent contents with other strong adult themes take over their psyche and control their actions.

- Adolescents should also try self-censorship; they should limit themselves from watching movies and shows that can trigger aggression and violent behaviours in them. Even though they may be young to even understand self-censorship, their parents or teachers could try to put them through and always remind them to be vigilant in their day to day choices.

\section{How to Cite this Article:}

Oyama, O.-A., \& Ogbu, S. (2017, November 1). Television and Content Censorship: The Impact of Violent Content on the Developmental Stages in the Personality of the Nigerian Child. Advanced Journal of Social Science, 1(1), 30-39. https://doi.org/10.21467/ajss.1.1.30-39

\section{References}

Adegbokun, D. (1983). Nigerian Television Authority. Television Journal, 3-5.

Adekoya, J. A., \& Ogunola, A. A. (2014). Childhood aggression in Ogun state, Nigeria: Fallout from violent movies showing. Social Sciences, 162-169.

Akpabio, E. (2003). Themes and conflict of Nigerian home video movies . Unilag Personality and Social Psychology, 589-595.

Apologetics Press. (2001). The origin of the soul. Montgomery: Apologetics Press Incorporated.

Augustus, D. (2015). The effects of globalisation on Nigerian youths and the economy. International Journal of Environment and Polution Research, 9-16.

Bandura, A. (1971). Social learning theory. New York: General learning press.

Bandura, A. (1977). Social learning theory. Englewood Cliffs: Prentice Hall.

Bandura, A., Ross, D., \& Ross, S. A. (1961). Transmission of aggression through the imitation of aggressive models. Journal of Abnormal and Social Psychology, 575-582.

Benson, R. (2008). Journalism: Normative theories. New York: New York University.

Brown, N. J., \& Bassey-Duke, V. (2014). Hollywood imperialism on Calaba-South teenagers- The score sheet. British Journal of Psychology Research, 11-25.

Chibuokwu, E. F. (2013). Influence of televised violence on social emotional and academic adjustment of students in federal tertiary institutions in Anambra state. Enugu: University of Nigeria.

Christakis, D. A., \& Zimmerman, F. J. (2007). Violent television viewing during preschool is associated with antisocial behaviour during school age. Paediatrics, 993-999.

Cohen, M. (2008). Aristotle on the soul. Washington: University of Washington.

Cunningham, S. (2001). From cultural to creative industries, theory, industry and policy implications'. Culturelink Special Issue, 19-32.

Dawson, A. (2009). Hollywood for Historians. Coventry: The Higher Education Academy.

Dixon, V. K. (2009). Understanding the implications of a global village. Retrieved from Inquiries Journal/Student Pulse: http://www.inquiriesjournal.com/a?id=61

Ebijuwa, T. (1999). Ethnic conflict, social dislocation and the search for a new order in Africa. In Anthropology of Africa and the challenges of the third millenium-ethnicity and ethnic conflicts. Most Ethno-net Publications.

Egbon, M. (1982). Origin and development of television broadcasting in Nigeria. Television Journal, 27-28.

Enna, D. M., Idakwo, E. P., \& Akpovye, O. D. (2015). The impact of the "magic" in Nollywood: An analysis . American International Journal of Contemporary Research, 177-187.

Eriksson, E. H. (1968). Identity, youth, and crisis. New York: Norton.

Federal Communications Commission. (2003, June). The technology of television. Retrieved from Federal Communications Commission: https://transition.fcc.gov/omd/history/tv/documents/76years_tv.pdf

Fleming, J. (2004). Psychosocial perspectives on human development. Prescott: Southwest Psychometrics and Psychological Resources.

Gabriel, O. (2016, March 7). Nigerians used scarce forex to kill textile industry. Retrieved from Vanguard Newspaper: http://www.vanguardngr.com/2016/03/nigerians-used-scarce-forex-to-kill-textile-industry/

Gentile, D. A. (2013). Catharsis and media violence: A conceptual analysis. Societies, 491-510.

Govier, T. (2008). Violence, nonviolence and, definitions: A dilema for peace studies. The Canadian Journal of Peace and Conflict Studies, 61-83.

Lessig, L. (1999). The censorship of televison. Berkman Centre, Internet and Society, 1-33.

Moeller, B. (1996). Learning from television: A research review. New York: Center for Children and Technology.

Moore, N. (2013). Censorship is. Australian Humanities Review, 35-45.

Muhammad, M. (2011). Globalisation crisis and national security: A reflection on Nigeria textile industry. JORIND, 88-95.

National Broadcasting Commission. (2014, 9 28). Nigerian Television Authority. Retrieved from National Broadcasting Commission : http://www.nbc.gov.ng/broadcast.php?menu=1\&submenu=1 
Nnabuko, J. O., \& Anatsui, T. C. (2012). Nollywood movies and Nigerian youths- An evaluation. JORIND, $214-222$.

Nowell-Smith, G. (1996). The oxford of world cinema. Oxford: The Oxford University Press.

Nwauzor, A. (2014). Changing values in contemporary Nigeria. Educational Research International, 103-111.

Nwegbu, M. U., Eze, C. C., \& Asogwa , B. E. (2011, December 1). Globalisation of cultural heritage: Issues, impacts and inevitable challenges for Nigeria. Lincoln: University of Nebraska. Retrieved from http://unnllib.unl.edu/lpp.

Odukomaiya, E. I. (2014). Cartoons influence towards violence and aggression in school age children in Nigeria. Gazimagusa: Institute of Graduate Studies and Research.

Oh, E. (2014). Nigeria's film industry: Nollywood looks to expand globally. United States International Trade Commission.

Ojukwu, C., \& Ezenandu, P. (2012). A paradigm shift from traditional to modernity in nollywood's projection of African narratives. Global Journals Incorporation, 20-26.

Okoroji, T. (2013). The Nigerian music industry. No Music Day (pp. 1-9). Ikeja: Nigeria Industry Music Coalition.

Oladipo, O. (1998). Modernisation and the search for community in West Africa. In O. Oladipo, Remaking Africa: Challenges of the twentyfirst century. Ibadan: Hope Publications.

Oluyemi, F. (2015). Transnational and integrative cultural roles of nollywood entertainment media in West Africa: The case study of Benin Republic and Ghana. International Journal of International Relations, Media and Mass Communication Studies, 34-41.

O'Moore, M. (2002). Defining violence: Towards a pupil based definition. Dublin: European Commission.

Opeyemi, F. K. (2008). Nollywood portrayal of the Nigerian society. International Journal of Communication, $282-290$.

Orunmoluyi, T. P. (2000). Globalisation: A millenium challenge for Nigeria banks. The Economist, 31-32.

Osofsky, J. D. (1999). The impact of violence on children. New York: Guilford Press.

Osuji, I. (2012, 10 14). The Nigerian Culture and Traditions. Retrieved from Osuji Innocent: https://osujiinnocent.wordpress.com/nigeriaindependent/the-nigerian-culture-and-traditions/

Pisharody, A. (2013). The Future of Television: Will broadcast and television networks survive the emergence of online streaming? New York: New York University.

Rishante, P. S., \& Yakubu, I. M. (2014). Children, sex and media violence in Nigeria. African Research Review, 43-55.

Rudinow, J. (2010). Soul music: Tracking the spiritual roots of pop from Plato to Motown. Michigan: The University of Michigan Press.

Scholtre, J. (1997). The globalisation of world policies. In S. Smith, \& J. Baylis, The globalisation of world policies. Oxford: University .

Shimamura, A. P. (2002). Muybridge in motion: Travels in art, psychology, and neurology. History of Photography, 341-350.

Shteyman, J. (2015, February 4). From the kinetoscope to the gopro. Retrieved from Sugarspace: https://barry-spectorq8ge.squarespace.com/s/Shteyman-JuliaFrom-the-Kinetoscope-to-the-GoPro-with-timeline.pdf

Slater, M. D., Henry, K. L., Swaim, R. C., \& Anderson, L. L. (2003). Violent media content and aggressiveness in adolescents: A downward spiral model. Communication Research, 713-736.

Sokol, J. T. (2009). Identity development through a lifetime: An examination of Eriksonian theory. Graduate Journal of Counselling Psychology, 1-11.

Soyinka, W. (1988, October 24). Twice bitten: The fate of Africa's culture producers. Development and culture. Ota, Ogun State, Nigeria: Africa Leadership Forum.

Steger, M. B. (2003). Globalisation: A very short introduction. Oxford: OUP.

Umeh, C. C. (1989). The advent and growth of television broadcasting in Nigeria: Its political and educational overtones. African Media Review, 54-66.

Villani, S. (2001). Impact of media on children and adolescents: A 10-year review of the research. Journal of American Academy of Child \& Adolescent Psychiatry, 392-401.

Villanueva, V. (1993). Antonio Gramsci and the idea of "hegemony". Illinois: National Council of Teachers of English.

Publish your research article in AIJR journals-

$\checkmark$ Online Submission and Tracking

$\checkmark$ Peer Reviewed

$\checkmark$ Rapid decision

$\checkmark$ Immediate Publication after acceptance

$\checkmark$ Open Access (Articles freely available online)

$\checkmark$ Retain full copyright of your article.

Submit your article at journals.aijr.in 